Fourth International Conference on Sustainable Construction Materials and Technologies http://www.claisse.info/Proceedings.htm

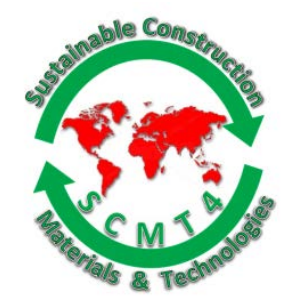

SCMT4

Las Vegas, USA, August 7-11, 2016

\title{
The Role of Cementitious Materials in the Next Decade
}

\author{
Antonio Nanni
}

University of Miami - Coral Gables, FL, USA 33146. E-mail: nanni@miami.edu.

\begin{abstract}
This paper presents a personal perspective on the potential impact of cementitious materials in the construction industry over the next decade. While it is true that today concrete and its derivatives are ubiquitous, their presence and use can only grow as academia and industry address the challenges of sustainability and resilience. The paper briefly discusses some of the topics that will fuel this growth and can be considered low-hanging fruits. They include: a) new classes of binders complementing portland cement; b) additives that transform fresh properties; c) non-corrosive reinforcement resulting in concrete without chloride limits; d) use of saltwater and recycled/alternative aggregates; and, e) brittle matrix composites for repair. Many other cutting-edge technologies such as nano-materials, ultra-high performance concrete, self-healing concrete, engineered cementitious composites and 3-D printing are not discussed as their impact will be most likely felt in the following decades. Advances and deployment of technology will make the concrete industry greener and more conscious of its environmental impact while, at the same time, providing means and methods to extend the useful life of existing concrete structures.
\end{abstract}

\subsection{INTRODUCTION}

\subsection{Topics of Interest}

No-one has a crystal ball to predict the future course of the construction industry; however, my personal opinion is that concrete and its derivatives will have a stronger presence and use in the next decade and the ones to come. Even though it may be counterintuitive, this is because of the central role that sustainability and resilience will play in shaping policies and technologies intended to address public safety and preservation of the environment. The paper only covers techniques and processes that can be considered to have reached a level 9 of the NASA technology readiness scale (TRS) or be already commercially deployed. Other promising technologies such as nano-materials, ultra-high performance concrete, self-healing concrete, engineered cementitious composites and 3-D printing are not discussed herein being at lower levels of the TRS scale. The paper will briefly address the following:

- A significant step towards sustainability is in the recycling of waste materials. The concrete industry has pioneered this effort by employing a wide variety of wastes as supplementary cementitious materials (SCMs) and mineral admixtures. Fly ash from coal combustion, ground granulated blast furnace slag from steel manufacturing, and silica fume from ferrosilicon production are the most widely used SCMs in addition to geopolymers. 
- Advances in the understanding of the rheology of concrete and its chemical reactions have produced a wide variety of chemical admixtures including water reducers, retarding and accelerating agents, super plasticizers, air entraining agents, corrosion inhibitors, shrinkage reducers and viscosity modifiers. These admixtures have resulted in improved workability, durability and strength of concrete and, most, relevant have made possible self-consolidating concrete (SCC).

- Technology developed over the last two decades has facilitated the use of advanced composite materials to replace "black" steel and epoxy coated steel reinforcement for concrete when the durability of a structure is of concern. The elimination of concrete corrosion has created the opportunity for production of concrete without chloride limits. This would open the door to greener and less costly cement manufacturing (e.g., use of solid wastes as fuel in the production of clinker).

- If standards were to permit seawater for mixing and curing concrete, and if natural/recycled aggregates could be used without freshwater pre-washing, we could save critical resources in coastal areas where the impact of rapid infrastructure growth and climate change are most pronounced. Additionally, the use of unwashed natural aggregates could prove to be more economical and ecologically-acceptable than riverbed extraction or inland mining. It should be noted that, if the current practices of concrete preparation continue unaltered, more and more freshwater supplies, critical for human survival will be depleted. Currently, the concrete industry uses about 1.5 trillion liters of freshwater annually.

- Cement-based materials can also play a critical role in the repair, rehabilitation and upgrade of the existing building stock and infrastructure. Perhaps the greatest impact they can have is in improving the performance of unreinforced masonry structures in regions of the world prone to seismic events. The deployment of a new generation of cementitious matrix composites may have an equivalent if not greater impact than that of externally-bonded fiber-reinforced polymer (FRP) composites.

\subsection{Sustainability and Resilience}

It is well known that concrete is only second to water as the most used material worldwide while the manufacturing of portland cement accounts for at least 5\% of global $\mathrm{CO}_{2}$ emissions (Boden et al. 2013), the worst possible carbon footprint of any construction material. Unfortunately (or fortunately, if one reverses a challenge to an opportunity), the other two key constituents of concrete (i.e., water and aggregates) also have an impact on sustainability. According to the World Health Organization; (http://www.who.int/mediacentre/factsheets/fs391/en/) "By 2025, half of the world's population will be living in water-stressed areas" and natural aggregates are being depleted at alarming rates. The challenges posed by addressing environmental threats and resource scarcity have created the opportunity to reinvent what half a century ago we took for granted. Apart from the negative environmental effects of consuming great amounts of freshwater and riverbed/mined aggregates, transportation of both is expensive and environmentally detrimental.

Reinforced concrete has proven not be as durable as once hoped primarily due to the corrosion of the steel reinforcement. It is estimated that steel corrosion costs any developed country around 3\% of its GDP. The American Society of Civil Engineers (ASCE) estimated in 2013 that \$3.6 trillion would be needed from 2013 to 2020 to maintain a state of good repair for the US infrastructure. The situation is worst along coastlines where cities rely heavily on their marine infrastructure (e.g., ports, bridges, artificial islands and offshore wind farms) for their socio-economic prosperity.

When looking at resilience and with particular reference to North America, we have recently witnessed the havoc caused by floods, tornadoes and fires. Climate change and population growth can only exacerbate these disastrous outcomes unless we take a different approach at how we build and what we build with our homes, schools and commercial structures. Concrete construction is the obvious response to the demands imposed by these events and, if not the final and total answer, certainly the most immediate, logical and economical one. There are additional examples that demonstrate how solidified construction practices that make little sense in the $21^{\text {st }}$ century can impact our sustainability, not necessarily from the perspective of 
safety, but in terms of economics. For example, when considering wood structures, termite damage and control in the State of Florida alone is reported by official statistics to be a staggering half a billion dollar annually.

\subsection{NEW CONSTRUCTION}

\subsection{New Binders}

Incredibly interesting and promising research is being conducted on alternative binders that can complement and partially replace portland cement such as fly ash, ground granulated blast furnace slag, silica fume and geoplymers.

Fly ash is a by-product of coal combustion. It is a fine powder collected from the exhaust gas by precipitation. ASTM C618 (2015) subdivides fly ash into two groups based on coal source and bulk chemistry as either Class $\mathrm{C}$ or Class F. Class F is pozzolanic and contains lower amounts of calcium, while Class C exhibits both self-cementitious and pozzolanic characteristics due to high calcium content (Cain 1981). The use of fly ash improves workability, permeability and long-term strength and decreases heat of hydration. Alkali-silica reaction (ASR) and sulfate resistivity of concrete can also be enhanced by using Class F fly ash (Dunstan 1980; Carrasquillo and Snow 1987).

Ground granulated blast furnace slag is a by-product of the steel industry. Dependent on the manufacturing process, it could exhibit both cementitious and pozzolanic characteristics (Tasong et al. 1999). Durability issues of concrete in aggressive environments such as sulfate attack, chloride diffusion and ASR can be addressed by using slag in the concrete mixture. Furthermore, it improves workability and long-term strength and reduces heat of hydration (Dhir et al. 1996; Higgins 2003; Hester et al. 2005).

Silica fume is a by-product of the silicon industry, which contains more than $85 \%$ silicon dioxide. Silica fume particles are spherical in shape and about 100 times smaller than cement grains (Buck and Burkes 1981). It can greatly decrease permeability and workability and increase compressive strength. It also provides resistance to sulfate attack and alkali-silica reaction (Malhotra et al. 1987).

Geopolymers are made by activating by-product materials such as fly ash, slag, or metakaolin that are rich in aluminum and silica by an alkaline solution (Davidovits 1999). Alkali-activated binders or geopolymers have been receiving significant attention because of their ability to replace portland cement in concrete and act as an alternative cementitious material. High strength, durability and low environmental impact of geopolymer concrete have been shown by many studies (Duxson et al. 2007).

\subsection{Non-conventional Aggregates}

Desert sand. Desert sand may be regarded as a source of fine aggregates in concrete (Zhang et al. 2006), especially for most of the countries which lack other suitable aggregates. In fact, desert sand has a similar $\mathrm{SiO}_{2}$ content as ordinary sand, similar density and does not include organic materials. Due to the abundance of such fine aggregate in some regions of the world, this alternative could decrease transportation costs, promote the use of local resources, reduce construction costs, reduce the need for ordinary sand and, due to its cleanness, reduce the amount of water for pre-washing. For instance, in a country like Oman, approximately $25 \%$ of the nation is covered by desert where industrial activities such as oil production require intense concrete construction (Al-Harthy et al. 2007).

Even though national specifications do not include the possibility of using very fine desert sand, some experimental results (Zhang et al. 2006) indicate that it can be readily utilized in concrete. The major effect of the very fine sand in the mixture is on workability; however, when in certain proportions, it may result beneficial to SCC formulations (Rmili et al. 2009).

Offshore aggregates. Offshore sand (i.e., extracted few kilometers away from the coastline), represents a valid alternative to ordinary sand in terms of abundance, ease of extraction, cost and environmental impact. The potential environmental damage (and freshwater exploitation) due to extraction operations appears 
smaller than that of riverbed sand extraction, especially if offshore sand does not require pre-washing (to remove salt, organic matter and other contaminants). Laboratory investigations on offshore sand obtained from American and European coasts have indicated that these materials can be successfully used for pavements and road construction (Huinguang et al. 2011; Kamali et al. 2008; Zentar et al. 2008). In some instances, it has been reported that the grading of the offshore sand is within the limits specified by existing construction specifications (Dolage et al. 2013). In addition, compressive strength of concrete made with this sand has been shown to be within acceptable limits for quantities of salts. Efflorescence and the corrosion of reinforcement could be avoided by pre-washing, but this would lead to an additional burden (Dolage et al. 2013). Chlorides limit-free reinforced concrete would be an appealing solution for cost reduction.

Recycled Concrete Aggregate (RCA): Worldwide, construction and demolition wastes make about 30\% of the total solid waste (Lauritzen 2004). In the US only, the annual construction and demolition waste ranges from 250 to 300 million tons (Leigh and Petterson 2004), of which concrete, asphalt and masonry represent about $23 \%$ of the total construction waste. The discarding of such large quantities in landfills is problematic. Unless recycled, the yearly accumulation of these wastes could cause significant economic and environmental problems. Concrete waste is mostly collected from structures demolished for renovation or reconstruction purposes. Due to the growing scarcity of natural aggregates, the use of RCA from demolished structures could be an ideal substitute thus mitigating the need for landfill space and new aggregate quarries. Use of RCA started decades ago in non-structural applications. R\&D is now being conducted to determine how viable RCA is as replacement of conventional aggregate in concrete construction with the primary purpose of making construction more environmentally friendly. In fact, construction "takes $50 \%$ of raw materials from nature, consumes $40 \%$ of total energy, and creates $50 \%$ of total waste" (Oikonomou 2005). RCA characteristics are influenced at large by the residual adhered mortar (McNeil and Kang 2013). RCA is more porous, less dense, and has a greater water absorption capacity than conventional aggregate. However, in spite of lower quality, laboratory testing has shown that RCA can be used in concrete construction.

Since the quality of RCA varies among diverse sources, there is concern about high chlorides content in RCA obtained from the demolition of structures subjected to de-icing salts. These structures include pavements, bridge decks and parking garages. If the steel reinforcement durability were not an issue, RCAbased concrete would be a suitable construction material regardless of RCA source. Use of RCA would then become especially attractive in the case of the transportation infrastructure when demolition of saltcontaminated obsolete structures and subsequent reconstruction is required.

Factors influencing the properties of a mixture containing RCA include: the quality and amounts of the cement paste or mortar adhered to the aggregate; the mortar/aggregate interfacial behavior; the RCA percentage that will replace aggregates; and, the mixing procedure (Vázquez 2013; Poon et al. 2004; Tavakoli and Soroushian 1996). There is a general consensus on the relatively higher permeability and diffusivity of RCA. The porosity of RCA is about twice that of ordinary concrete (Gomez-Soberon 2002) due to the porosity in the cementitious matrix and the original aggregate. This could make RCA prone to attack from aggressive chemicals such as sulfates and chlorides as well as exhibit alkali-silicate reaction. Several studies have been carried out over the past decades to mitigate this problem by adding admixtures such as silica fume, and fly ash blast furnace slag.

\subsection{Seawater}

The use of seawater is attractive because it is convenient and economical especially in coastal areas. Despite the potential advantages (in the perspective of sustainability goals), the use of seawater is currently prohibited. Typically, seawater has a total salinity of $3.5 \%$, of which $78 \%$ is sodium chloride. The presence of chlorides in seawater affects the early stages of hydration of portland cement (and workability, consequently) and the long-term development of strength, with some risk of alkali-aggregate reactions with 
susceptible aggregates (Neville 2001). However, the sole reason prohibiting the use of seawater is the early corrosion of steel reinforcement.

Even though the use of seawater is currently prohibited, different studies have shown promising results. Concerning fresh concrete properties, some research efforts suggested that the use of suitable chemical admixtures could lead to appropriate workability (Kaushik and Islam 1995). Furthermore, it has been demonstrated that the effect of mixing water is insignificant particularly after exposure of 20-year. Other technical literature reports that salt in seawater has no significant negative effects on the fresh and hardened characteristics of concrete even when poor-quality aggregates are used (Hime 2007). Promising outcomes have been achieved when mineral admixtures, such as blast furnace slag, are added to the concrete mix design (Fukute et al. 1990).

There is a number of structures along the coasts of South California and Florida built with seawater concrete. This is proof of the possible use of seawater in concrete mix. Where durability problems are present, they generally are related to the corrosion of steel reinforcement (Kaushik and Islam 1995). Uddin Mohammed (2003) conducted a study on specimens made of different mixtures immersed in a saltwater pool. This environment tried to recreate the tidal zone in the laboratory. The effects of these conditions were studied at different ages. The results showed an increase in the compressive strength for the first five years, followed by a gradual reduction until the tenth year, while at 20 years, the strength approaches the value of the 28-day strength. It was concluded that the presence of seawater in the mixes did not affect the long-term compressive capacity.

The influence of concrete shrinkage was investigated by Park and co-workers (2011). Mixes with different chloride content were evaluated showing that water loss of concrete, as well as strength and Young's modulus are insignificantly affected by the $\mathrm{NaCl}$ content in the concrete. However, because of the higher shrinkage, chlorides are responsible for a reduced cracking time. ACI 201.2R-08 Guide to Durable Concrete (2008) recommends a maximum chloride content of $0.20 \%$ by cement mass, for reinforced concrete placed in dry or protected environmental conditions. The corresponding ratio of the chloride content for the case of reinforced concrete placed in wet environmental condition is $0.1 \%$ by cement mass.

\subsection{Reinforcement}

Steel Bars: Steel corrosion within concrete structures is one of the main causes of infrastructure degradation. Typically, concrete provides a safe environment for steel, protecting it from corrosion and other forms of deterioration. However, this protection can deteriorate when chlorides are present within the concrete. These chlorides can come from the external environment, typically through the application of de-icing salts or exposure to seawater, or the chlorides can be placed in the concrete while mixing.

The critical chloride content, $\mathrm{C}_{\text {crit }}$ (also referred to as the chloride threshold) is defined as the concentration that causes the steel to transition from a passive state where no corrosion is occurring, to an active state, where corrosion can begin. $\mathrm{C}_{\text {crit }}$ is a very important property as it is used in service life modeling to predict when corrosion will initiate. It is also used as the basis for codes and specifications to determine allowable internal chloride levels at the time of construction. Significant research effort has been devoted to the determination of $\mathrm{C}_{\text {crit }}$ for ordinary portland cement concrete (Angst et al. 2009).

GFRP Bars: Glass fiber reinforced polymer (GFRP) bars are made of continuous fibers impregnated in a polymeric resin matrix via the pultrusion process (Nanni et al. 2014). The load is carried by the fiber and transferred by the resin. The resin (typically a vinyl ester because of its adequate mechanical characteristics and superb durability) also protects and binds the fibers together. Glass is the most commonly used fiber with many advantageous characteristics. GFRP is of high strength and high chemical resistance and it is relatively of low cost when compared to other fibers such as carbon. GFRP is also characterized by its good thermal and electrical insulating properties. The weight of FRP is about one-fifth that of steel. This is particularly useful for reducing the cost of transportation and for handling bars at the job site. However, 
GFRP has some drawbacks such as low modulus of elasticity and relatively low fatigue resistance when compared to steel. The tensile stress-strain relationship of GFRP bars is linear elastic up to failure.

The mechanical properties of a GFRP bar are affected by environmental conditions. The tensile/bond characteristics of GFRP, may be affected by moisture, acidic or alkaline solutions, salinity, extreme temperature or ultraviolet exposure. Tensile test, interlaminar shear test and pullout test were performed on specimens exposed to different environments (Chen et al. 2007). The results showed that the GFRP bars lose strength when exposed to aggressive environments: a greater degradation was obtained with continuous immersion. On the other hand, freeze and thawing had negligible effects on GFRP.

In various studies, it was shown that with an increase of the temperature the effect of the environment on the GFRP becomes stronger. The loss in strength for bars of diameter equal to $12.7 \mathrm{~mm}$ in seawater was about $13 \%$ to $57 \%$, depending on both fiber/resin type (E-glass/ vinyl ester or E-glass/ modified vinyl ester) and temperature (tests were performed at 25,40 and $80^{\circ} \mathrm{C}$ ). The tensile test response of the GFRP bars subjected to two diverse environments typical field conditions of the Kingdom of Saudi Arabia was investigated (Al-Salloum et al. 2013). These two environments reproduced the conditions of hot-dry weather (with monthly average temperature between 9 and $45^{\circ} \mathrm{C}$ and an annual average humidity of 26\%) and hot-humid one (with the same monthly average temperature but an annual average humidity of 52\%). Using linear regression as a preliminary prediction, it was found that the average tensile strength falls below a critical limit after 75-90 years under those conditions.

Mathieu and Benmokrane (2013), focused on durability of GFRP bars when they are embedded in concrete and immersed in a saline solution. The objective was to simulate seawater environment and the effect of deicing salts for tests conducted on samples subjected to accelerated conditions. Comparing the results obtained for bars immersed in salt and freshwater, the effects of these two different environments on GFRP resulted not relevant. After 100 years (according to the Arrhenius model), the tensile strength retention was predicted at $70-77 \%$.

\subsection{Examples of Research Projects}

Three research projects in different regions of the world (i.e., EU-USA, Qatar, and Hong Kong) are the expression of research work being conducted on the next generation of reinforced concrete. They are at different stages of development (the first one has started, the second one was selected for funding, and the third one is at the final stages of competition). The common denominator among the three is the deployment of concrete without chloride limits using reinforcement that has the attribute of being corrosion-free. Unfortunately, modern structures because of economics, efficiency, magnitude, safety and construction time cannot afford to use unreinforced concrete like Romans did: only one Parthenon was ever built!

The use of non-corrosive reinforcement in combination with saltwater or sea-aggregates has been recently explored in small-scale projects (e.g., project led by X.L. Zhao of Monash University in Australia and three projects funded in 2015 by the Natural Science Foundation of China) and a few publications have appeared on the subject (Teng et al. 2011; Teng 2014; Feng et al. 2014; Selicato et al. 2015; Xie et al. 2015).

The use of non-corrosive reinforcement in a concrete without chloride limits has a number of major sustainability/economic benefits:

a. the steel corrosion problem is eliminated and the service life is enhanced, reducing wastes and carbon emissions as well as avoiding frequent demolition/reconstruction activities;

b. the use of non-corrosive reinforcement has the additional benefit that it is no longer required to use freshwater and riverbed/mined sand; and,

c. the removal of chloride thresholds imposed on cement will allow the use of solid wastes irrespective of chloride content as alternative fuels in clinker production.

The recently funded EU-USA project will culminate with two real-size demonstrations, one in Italy and 
one in Florida, at locations with very different (micro) climates (continental away from the coastline and subtropical along the coastline), addressing two different infrastructure elements (reinforced concrete culverts and a bridge, the Halls River Bridge). These demonstrations represent critical elements of the transportation infrastructure and will provide the opportunity for long-term monitoring. In particular, the Halls River Bridge consists of five 11.3-m simply supported spans. Its super- and sub-structure are exposed to extremely aggressive environments due to proximity to the seawater level so that the use of non-corrosive reinforcement addresses long-term durability of cast-in-place and precast concrete members. Provisions have been made for collecting samples from the bulkhead cap over time for durability assessments.

\subsection{REPAIR AND REHABILITATION}

\subsection{Fabric Reinforced Cementitious Matrix and Steel Reinforced Grout}

The concrete repair industry in North America is a multi-million dollar enterprise. Its primary market is that of repairing and rehabilitating deteriorated concrete structures due to steel reinforcement corrosion. If one wanted a confirmation of its current relevance two things come to mind: a) we have a technical organization (i.e., the International Repair Concrete Institute (ICRI)) solely devoted to this problem; and, b) two bellwether organizations (i.e., International Organization for Standardization (ISO) and American Concrete Institute (ACI)) have recently published for the first time repair design and construction standards (ISO 2014; ACI 562-13).

In addition to concrete repair, we have to address the vulnerability of unreinforced masonry structures (both historical and not). The lead technology that was conceived and fully deployed in the last three decades is that of externally bonded FRP systems. I am, however, convinced that the next decade will witness an explosion of relatively newer tools for strengthening of deficient structures, would they be concrete or masonry construction (Nanni 2012; Huang et al 2005). The new tools have in common a cementitious matrix and are known under the acronyms of FRCM (fabric reinforced cementitious matrix) and SRG (steel reinforced grout) (AC434 2016). FRCM and SRG are two composites consisting of a sequence of one or more layers of cement or hydraulic lime matrix reinforced with fabrics in the form of open grids. For FRCM, the open grid is a fabric of strands made of fibers such as aramid, alkali resistant (AR) glass, carbon, basalt or polyparaphenylene benzobisoxazole (PBO). For SRG, the fabric is made of woven cords of twisted micro wires. The twisting of the individual wires to form the chords provides an interlocking mechanism with the mortar to enhance bond.

\subsection{CONCLUSIONS}

The contents of this paper can be seen as a review of some technical solutions intended to address now and in the immediate future the challenges of sustainability and resilience that we face as a modern society. The discussion is limited to cement-based materials from concrete for new construction to strengthening systems that have been recently implemented or are almost ready for full commercial deployment. The take-away point of the paper is that in addressing these challenges and transforming them into opportunities, the use of concrete and its derivatives will become even more ubiquitous.

Concrete as a construction material is benefitting from transformational research to complement portland cement with other binders that have a smaller $\mathrm{CO}_{2}$ footprint. Advances in understanding the role of supplementary materials and additives' chemistry are transforming the fresh properties of concrete giving it the ability to self-consolidate and be pumped without segregation as if it were a homogeneous fluid. The availability of FRP composites as internal reinforcement will remove the need to limit chloride content in concrete and extend its useful life beyond the 100-year target. Additionally, concrete without chloride limits will open the path to the use of seawater, unwashed offshore aggregates and RCA in regions of the world plagued by scarcity of freshwater and natural resources.

Concrete technology is an obvious response to the challenges of resilience in areas of the world, including North America, where the devastating effects of natural disasters have become an unsustainable toll for the 
safety and prosperity of our communities. This will require a transformation of current construction practices that utilize seemingly cheaper materials.

Finally, cement-based brittle-matrix strengthening systems can play an important role in the repair and rehabilitation of buildings and the civil infrastructure. In particular, the seismic upgrade of unreinforced masonry structures is one of the most compelling areas of intervention.

\section{ACKNOWLEDGEMENTS}

The author wishes to acknowledge the financial support received from several organizations for the research conducted at the University of Miami: Infravation Program under Grant Agreement No. 31109806.005SEACON; University Transportation Center RE-CAST under Grant Agreement DTRT13-G-UTC45; National Science Foundation (NSF) Industry/University Center for Integration of Composites into Infrastructure (CICI) under Grant IIP-1439543; and, Qatar National Research Fund (a member of Qatar Foundation) under NPRP Grant \# 7-1720-2-641. The opinions in this paper are those of the author and not necessarily those of the sponsors or collaborators.

\section{REFERENCES}

Al-Harthy, A.S., Abdel Halim M., Taha R., and Al-Jabri K.S. (2007). "The properties of concrete made with fine dune sand,” Construction and Building Materials, 21, pp. 1803-1808.

Al-Salloum, Y. A., El-Gamal, S., Almusallam, T. H., and Alsayed, S. H. A. M. (2013). "Effect of harsh environmental conditions on the tensile properties of GFRP bars." Composites, 45 B, pp. 835 -844.

American Concrete Institute (ACI) Committee 201. (2008). Guide to durable concrete. ACI 201.2R-08, Farmington Hills, MI.

American Concrete Institute (ACI) Committee 209. (1997). "Prediction of creep, shrinkage and temperature effects in concrete structures." ACI Committee Report, 76, pp. 193-300.

American Concrete Institute (ACI) Committee 562. (2016) "Code Requirements for Assessment, Repair, and Rehabilitation of Existing 3 Concrete Structures (ACI 562-16) and Commentary,” ACI 562-16, Farmington Hills, MI.

Angst, U., Elsener, B., Larsen, C.K., and Vennesland, O. (2009). “Critical chloride content in reinforced concrete - A review.” Cement and Concrete Research, 39, pp. 1122-1138.

ASTM C618-15 (2015) "Standard Specification for Coal Fly Ash and Raw or Calcined Natural Pozzolan for Use in Concrete”, ASTM International, West Conshohocken, PA.

Bertolini L., Elsener B., Pedeferri P., and Polder R. (2000). Corrosion of steel in concrete: Prevention, diagnosis, repair, WILEY-VHC Verlag GmbH\&Co, Weinheim, Germany.

Boden, T. A., G. Marland and R. J. Andres (2013). Global, Regional, and National Fossil-Fuel CO2 Emissions. Oak Ridge, Tenn., USA, Carbon Dioxide Information Analysis Center (CDIAC), Oak Ridge National Laboratory, U.S. Department of Energy.

Cain, C. J. (1981) "Effects of Various Types of Fly Ash on Behavior and Properties of Concrete," Effects of Fly Ash Incorporation in Cement and Concrete, Proceedings, Symposium N, Materials Research Society, pp. 260-268.

Carrasquillo, R. L. and Snow, P. G. (1987) "Effect of Fly Ash on AlkaliAggregate Reaction in Concrete," ACI Materials Journal, pp. 299-305

Davidovits, J. (1999) "Chemistry of Geopolymeric Systems, Terminology,” Geopolymer '99 International Conference, France, pp. 9-40.

Dhir, R.K., El-Mohr M.A.K., Dyer T.D. (1996) “Chloride binding in GGBS concrete," Cement and Concrete Research, 26 (12): 1767-1773.

Dolage, D. A. R., Dias, M. G. S., and Ariyawansa, C. T., (2013). "Offshore sand as a fine aggregate for concrete production." British Journal of Applied Science \& Technology, 4(3), pp. 813-825.

Dunstan, E. R., Jr. (1980) "A Possible Method for Identifying Fly Ashes that Will Improve the Sulfate Resistance of Concretes,” Cement, Concrete, and Aggregates, Vol. 2, No. 1, pp. 20-30.

Duxson, P., Fernández-Jiménez, A., Provis, J.L., Lukey, G.C., Palomo, A., van Deventer, J.S.J. (2007) “Geopolymer technology: the current state of the art” Journal of Material Science, 42 (9), pp. 2917-2933

Feng, P., Wang, J., Zhang, X. and Ye, L.P. (2014). "Development and innovation on combining FRP and sea sand concrete for structures”, Fiber Reinforced Plastics/Composites, 12(1), 13-18 (in Chinese). 
Fukute, T., Yamamoto, K., and Hamada, H. (1990). "Study on the durability of concrete mixed with seawater", Report of the port and harbor research institute, Ministry of transport, 29(3), pp. 57-93

Gomez-Soberon, J.M.V. (2002). "Porosity of Recycled Concrete with Substitution of Recycled Concrete Aggregate," Cement and Concrete Research, 32, pp. 1301-1311.

Hester D, McNally C, Richardson M (2005) "A study of the influence of slag alkali level on the alkali-silica reactivity of slag concrete," Construction and Building Materials 19: 661-665.

Higgins DD (2003) "Increased sulfate resistance of GGBS concrete in the presence of carbonate," Cement and Concrete Composites 25: 913-919.

Hime, W.G. (2007). “Alkalies, Chlorides, Seawater and ASR,” Concrete International, 29 (8), pp. 65-67

Huang, X., V. Birman, A. Nanni, and G. Tunis (2005), "Properties and Potential for Application of Steel Reinforced Polymer (SRP) and Steel Reinforced Grout (SRG) Composites,” Composites, Part B, 36 (1), pp. 73-82.

Huinguang, Y., Yan, L., Henglin, L. and Quan, G. (2011). "Durability of sea-sand containing concrete: Effects of chloride ion penetration." Mining Science and Technology (China), 21, pp. 123-127.

ICC-Evaluation Service (2016), "Acceptance criteria for masonry and concrete strengthening using fabric-reinforced cementitious matrix (FRCM) and steel reinforced grout (SRG) composite systems," AC434, Whittier, CA.

ISO 16311-1, 2, 3, 4 (2014), "Maintenance and repair of concrete structures," Vol. 1 to 4, International Organization for Standardization, Geneva, Switzerland.

Kamali, S., Bernard, F., Abriak, N. E. and P., D. (2008). "Marine dredged sediments as a new materials resource for road constructions." Waste Management, 28, pp. 919-928.

Kaushik, S. and Islam, S. (1995). "Suitability of seawater for mixing structural concrete exposed to a marine environment." Cement and Concrete Composites, 17, pp. 177-185.

Lauritzen, E.K. (2004). "Recycling of concrete-an overview of development and challenges." International RILEM conference on the use of recycled materials in building and structures. RILEM Publications SARL; pp. 297-305.

Leigh N.G. and Patterson L.M. (2004). "Construction and demolition debris recycling for environmental protection and economic development, practice guide \# 7." Southeast Regional Environmental Finance Center, University of Louisville, Kentucky.

Malhotra, V. M., Ramachandran, V. S., Feldman, R. F., and Aitcin, P. C. (1987) “Condensed Silica Fume in Concrete”, CRC Press, Boca Raton, FL.

Mathieu, R. and Benmokrane, B. (2013). "Combined effects of saline solution and moist concrete on long-term durability of GFRP reinforcing bars." Construction and Building Materials, 38, pp. 274-284.

McNeil, K., and T.H.-K. Kang (2013). "Recycled Concrete Aggregates: A Review,” International Journal of Concrete Structures and Materials, 7(1), pp. 61-69.

Mehta, K. and Monteiro P. (2013). Concrete - Microstructure, Properties and Materials, McGraw-Hill Education, p. 704.

Nanni, A. (2012). “A New Tool in the Concrete and Masonry Repair," Concrete International, 34 (4), pp. 43-49.

Nanni, A., De Luca, A. and Jawaheri Zadeh, H. (2014). FRP Reinforced Concrete Structures - Theory, Design and Practice, CRC Press, p. 397.

Neville, A. (2001). “Seawater in the Mixture,” Concrete International, 23 (1), pp. 48-51.

Oikonomou, N. (2005). "Recycled concrete aggregates," Cement and Concrete Composites, 27, pp. 315-318.

Park, S. S., Kwon, S. and Song, H. (2011). "Analysis technique for restrained shrinkage of concrete containing chlorides." Materials and structures, 44(2), pp. 475-486.

Poon, C.S., Shui, Z.H., Lam, L., Fok, H., and Kou, S.C. (2004). "Influence of Moisture States of Natural and Recycled Aggregates on the Slump and Compressive Strength of Concrete," Cement and Concrete Research, 34, pp. 3136.

Rmili, A. Ouezdou M. B., Added M., Ghorbel E. (2009). "Incorporation of Crus Hed Sands and Tunisian Desert Sands in the Composition of Self Compacting Concretes Part I: Study of Formulation,” International Journal of Concrete Structures and Materials, 3(1), pp. 3-9.

Selicato, F., Moro, M., Bertolini, L. and Nanni, A. (2015). "Towards sustainability of concrete without chloride limits”, ACI Special Publication, 305, 1-10.

Tasong WA, Wild S, Tilley RJD (1999) "Mechanism by which ground granulated blast furnace slag prevents sulfate attack of lime stabilized kaolinite," Cement and Concrete Research 29: 975-982

Tavakoli, M. and P. Soroushian (1996). "Strengths of recycled aggregate concrete made using field-demolished concrete as aggregate." ACI Materials Journal 93(2). 
Teng, J.G. (2014). "Performance enhancement of structures through the use of fibre-reinforced polymer (FRP) composites", Proceedings, $23^{\text {rd }}$ Australasian Conference on the Mechanics of Structures and Materials (ACMSM23), Lismore, Australia (Abstract).

Teng, J.G., Yu, T., Dai, J.G. and Chen, G.M. (2011). "FRP composites in new construction: current status and opportunities”, Proceedings, $7^{\text {th }}$ National Conference on FRP Composites in Infrastructure (Supplementary Issue of Industrial Construction) (Abstract).

Uddin Mohammed, H. H. T. Y. (2003). "Performance of seawater-mixed concrete in the tidal environment." Cement and Concrete Research, pp. 593-601.

Vázquez, E. (Ed.) (2013) "Progress of Recycling in the Built Environment," Final report of the RILEM Technical Committee 217-PRE, Series: RILEM State-of-the-Art Reports, 8, XXIX, p. 284.

Xie, Y., Deng, J. and Lai, L. (2015). "Durability of BFRP mesh-reinforced sea sand mortar thin plate”, Proceedings, 2nd International Conference on Performance-based and Lifecycle Structural Engineering (PLSE 2015), Brisbane, Australia.

Zentar, R., Dubois, V. and Abriak, N. E. (2008). "Mechanical behavior and environmental impacts of a test road built with marine dredged sediments." Resources, Conservation and Recycling, 52, pp. 947-954.

Zhang, G., Song J., Yang J., Liu X. (2006) "Performance of mortar and concrete made with a fine aggregate of desert sand,” Building and Environment, 41(11), pp. 1478 -1481. 